\title{
A Comparative study of Extra-Amniotic Instillation of Ethacridine with Tablet Dinoprostone (PGE2) in Second Trimester Abortion Versus Ethacridine Alone
}

\author{
Kour S, ${ }^{1}$ Kour $\mathbf{G}^{2}$ \\ ${ }^{1}$ Dept of Obs/Gyn, Acharaya Sri Chander College of Medical Sciences, Sidhra, Jammu \& Kashmir, ${ }^{2} E S I C$ Hospital, Noida, Uttar \\ Pradesh, India
}

\begin{abstract}
Aims: To study the efficacy of combination of extra-amniotic instillation of ethacridine with tablets Dinoprostone (PGE2) in second trimester abortion as compared to ethacridine alone.

Methods: One hundred patients undergoing second trimester abortion were divided into two groups. Fifty patients received extra-amniotic ethacridine lactate $150 \mathrm{ml}$ through Foley's catheter (Ethacridine group) and the other 50 patients received $150 \mathrm{ml}$ extra-amniotic ethacridine lactate mixed with a $0.5 \mathrm{mg}$ of a crushed tablet of Dinoprostone through Foley's catheter (Combination group). Both the groups were compared in respect to instillation-abortion interval, completeness of abortion and success rate.
\end{abstract}

Results: The mean age, multiparity parity, and gestational age were comparable in both the groups. The instillation- abortion interval was significantly shorter in combination group as compared to ethacridine group $(16.4 \pm 7.1$ vs. $29.9 \pm 13.9$ hours, $\mathrm{p}<0.001)$. Two patients in combination group had instillation abortion interval more than 48 hours as compared to 16 patients in ethacridine group $(\mathrm{p}<0.0005)$. Forty one patients $(82 \%)$ in combination group had complete abortion as compared to $37(74 \%)$ patients in ethacridine group. The success rate was $48 / 50(96 \%)$ in combination group as compared to $45 / 50(90 \%)$ in ethacridine group.

Conclusions: Addition of a $0.5 \mathrm{mg}$ of crushed tablet of Dinoprostone in extra-amniotically instilled ethacridine lactate reduced the instillation-abortion interval significantly, increased the chances of complete abortion and increased the success rate.

Keywords: Dinoprostone, ethacridine lactate, extra-amniotic instillation, instillation-abortion interval

\section{INTRODUCTION}

Various methods of termination of pregnancy in second trimester have been tried. An ideal method should avoid complications like hemorrhage, infection and perforation with reduced hospital stay.

Extra- amniotic instillation of various substances has been carried out for termination of pregnancy for more than a

\section{CORRESPONDENCE}

Sandeep Kour, MD

Assistant Professor, Dept of Obs/Gyn

Acharaya Sri Chander College of Medical Sciences

Vasant Vihar, Extension Sector 3 Trikuta Nagar Jammu

Jammu \& Kashmir- India- 180012

Phone: 91-191-2470070

Email: sandeepkour06@yahoo.com century. Extra-amniotic instillation of abortifacients came into prominence with realization of dangers associated with their use through intra-amniotic route. ${ }^{1-3}$

Ethacridine lactate has long been used for second trimester abortion and is considered a time tested, safe and effective method. ${ }^{4,5}$ When used alone it has a prolonged inductionabortion interval and increased incidence of failure. In order to improve the efficacy of the procedure various 
other techniques and drugs have been combined with ethacridine. ${ }^{6,7}$ Prostaglandins have shown to be good abortifacients with ability to terminate pregnancy at any stage of gestation. Prostaglandin E2 and prostaglandin F2 $\alpha$ are now well known abortifacients. ${ }^{8}$ Problems with systemic use of prostaglandins are rapid metabolic inactivation requiring multiple dosings and systemic side effects like nausea, vomiting, diarrhea and decrease in the blood pressure. ${ }^{8,9}$ To overcome these problems prostaglandins can be given locally into the extra-amniotic space where the required effect can be produced with smaller doses and lesser side effects. The addition of prostaglandins to ethacridine in the extra-amniotic space is likely to decrease the induction-abortion interval. ${ }^{6,10}$

\section{METHODS}

After a detailed history, a complete physical examination was done to rule out any systemic disease. Patients with history of hypertension, previous uterine surgery, cardiac or renal disease, severe anemia and bronchial asthma were excluded. An ultrasound examination was done to confirm the gestational age. Only patients in the second trimester of pregnancy were enrolled into the study. Written informed consent was obtained from all the patients and 50 patients were kept in each groups:

Ethacridine group: Ethacridine lactate $150 \mathrm{ml}$ extraamniotic instillation with Foley's catheter .

Combination group: Ethacridine lactate $150 \mathrm{ml}$ mixed with crushed tablet of Dinoprostone ( PGE2) instilled extraamniotically .

In all the patients catheter was left in situ. If patient did not expel the catheter spontaneously or did not abort in twenty four hours, oxytocin drip was started after removing the catheter. When placenta was expelled spontaneously or with oxytocin drips within two hours of expulsion of fetus the abortion was considered complete. If the patient did not abort in seventy two hours the procedure was considered a failure and procedure was repeated. The results obtained in both the groups were compared in respect to instillation-abortion interval, completeness of abortion and failure of procedure. Student's $t$ test was used to compare the differences in the instillation abortion interval between the two groups and Fisher's exact test was used to test the differences between two groups for categorical data. The study was approved by Institutional Ethics Committee.

\section{RESULTS}

Fifty patients in the ethacridine only group and fifty patients in the combination (ethacridine and dinoprostone) group were recruited in the study. The mean age in both the groups was same i.e. 26 years. Sixty eight patients were multigravida. Mean gestational age in both the groups was
18.4 weeks with a range of $14-20$ weeks. There were no significant differences between the two groups as far as age, parity or gestational age was concerned. Most of the patients were multigravida. (Table 1)

\section{Table 1. Distribution of age, parity and gestational age}

\begin{tabular}{lrr}
\hline & $\begin{array}{l}\text { Ethacridine only } \\
(\mathrm{N}=50)\end{array}$ & $\begin{array}{l}\text { Co m b in a t i o n } \\
\text { Group }(\mathrm{N}=50)\end{array}$ \\
\hline Age & & \\
Mean \pm SD & $26.0 \pm 6.2$ years \\
Range & $18-40$ years & $18-36$ years \\
Parity & 15 & 17 \\
Primigravida & 35 & 33 \\
Multigravida & & \\
Gestational age & & $18.4 \pm 1.8$ weeks \\
Mean \pm SD & $18.4 \pm 1.5$ weeks \\
Range & $14-20$ weeks & $14-20$ weeks \\
\hline
\end{tabular}

Instillation abortion interval was significantly shorter in the combination group i.e.16.4 \pm 7.1 hours as compared to $29.9 \pm 13.1$ hours in the ethacridine only group $(p<0.001)$. Forty patients in the combination group had instillation abortion interval of less than 24 hours as compared to 19 patients in the ethacridine only group. (Table 2 )

Table 2. Instillation abortion interval

\begin{tabular}{lll}
\hline $\begin{array}{l}\text { Instillation } \\
\text { abortion interval }\end{array}$ & $\begin{array}{l}\text { Ethacridine only } \\
(\mathrm{N}=50)\end{array}$ & $\begin{array}{l}\text { Combination } \\
\text { Group }(\mathrm{N}=50)\end{array}$ \\
\hline$<24$ hours & 19 & $40^{*}$ \\
$24-48$ hours & 15 & 8 \\
$>48$ hours & 16 & $2^{* *}$ \\
Mean \pm SD & $29.9 \pm 13.1$ hours & $16.4 \pm 7.1$ \\
& & hours $* * *$ \\
\hline
\end{tabular}

${ }^{*} p<0.0001$ by Fisher's exact test

$* * P<0.0005$ by Fisher's exact test

$* * * \mathrm{P}<0.001$, students $\mathrm{t}$ test

Only two patients in the combination group had instillation abortion interval of more than 48 hours as compared to 16 patients in the ethacridine only group (Table 2 ). Forty one patients in the combination group had complete abortion as compared to 37 patients in the ethacridine group. Forty eight patients in the combination group had successful abortion as compared to 45 patients in the ethacridine only group. (Table 3 )

Table 3. Completeness of abortion and success rate

\begin{tabular}{lll}
\hline & $\begin{array}{l}\text { Ethacridine only } \\
(\mathrm{N}=50)\end{array}$ & $\begin{array}{l}\text { Combination } \\
\text { Group (N=50) }\end{array}$ \\
\hline $\begin{array}{l}\text { C o m p l e t e } \\
\text { abortion }\end{array}$ & $41(84 \%)$ & \\
Success rate & $45(90 \%)$ & $48(96 \%)$ \\
\hline
\end{tabular}




\section{DISCUSSION}

Extra-amniotic instillation of ethacridine lactate is a well accepted method of termination of second trimester of pregnancy. This is due to its efficacy and good safety profile. ${ }^{4,5}$ However instillation of extra-amniotic ethacridine is not without drawbacks like long instillation abortion interval and failures. Prostaglandins have strong oxytocic effect and thus are expected to shorten the abortion instillation interval. Prostaglandins have been used widely as abortifacients by various routes but have unwanted side effects such as uterine rupture, cervico-vaginal injuries, vomiting, diarrhea, and broncospasm..$^{8,9}$ Ethacridine when used in combination with extra-amniotic prostaglandins causes cervical ripening, softening and dilatation thus increasing the efficacy of the method and decreasing the side effects. ${ }^{10}$ Introduction of prostaglandins into the extra amniotic space decreases the drug requirement by $10-20$ times thus decreasing the systemic side effects of the drug.

Sixty eight out of hundred patients were multigravida (Table 1). This is a reflection of high fertility rates seen in the developing countries and has been reported in another study from India. ${ }^{11}$ Patients presenting in late second trimester for abortion reflect a delayed decision making and putting the patient at a higher complication rate as compared to abortion in the first trimester. ${ }^{12}$

The instillation abortion interval in the combination group was significantly shorter than the ethacridine group with $80 \%$ cases aborting within 24 hours while only half the patients in the Ethacridine only group aborted within 24 hours thus cutting short the instillation abortion interval. Ethacridine when used alone acts by stripping the amniotic membranes from the uterine wall leading to release of prostaglandins, reflex release of oxytocin and mechanical stimulation of the uterus. ${ }^{12,13}$ Ethacridine when used alone has an instillation abortion interval of about 24-40 hours which can be cut short to 15-20 hours with oxytocin infusion supplementation. ${ }^{6,12}$ The use of oxytocin is however associated with serious side effects like hyponatremia and water intoxication which could result in seizures.

Prostaglandins receptors are present in the uterus throughout the pregnancy thus prostaglandins are effective agents of termination of pregnancy during both the first and second trimesters. Prostaglandins also help in cervical ripening and dilatation making the process of termination of pregnancy smooth. ${ }^{14,15}$ A recent study from China showed increased efficacy of dinoprostone and ethacridine combination as compared to ethacridine only group. The patients in the combination group had significantly more efficacy, shorter duration of labor and less bleeding as compared to ethacridine only group. ${ }^{10}$

\section{CONCLUSION}

Addition of crushed tablets of dinoprostone along with extra- amniotic ethacridine shortened the instillation abortion interval significantly in termination of second trimester pregnancy. Since $80 \%$ of patients in the combination group aborted within 24 hours, they can be discharged after an overnight stay. It helps to cut short the hospital stay of the patients with slight increase in the cost of therapy. This is important in a developing country where females want to be back to their household duties at the earliest.

\section{REFERENCES}

1. Shearman RP, Lyneham RC, Walsh JC, Itzkowic D, Shutt DA Electroencephalographic changes after intra-amniotic prostaglandin F2alpha and hypertonic saline. Br J Obstet Gynaecol. 1975;82(4):314-

2. Kafrissen ME, Schulz KF, Grimes DA, Cates W Jr. Mid trimester abortion. Intra-amniotic instillation of hyperosmolar urea and prostaglandin F2 alpha vs.dilatation and evacuation. JAMA. 1984;17(7):916-9.

3. Lange AP. Prostaglandins as abortifacients in Denmark. Acta Obstet Gynecol Scand Suppl. 1983;113:117-24.

4. Shukla S, Sapre S, Olyai P. Mid-trimester pregnancy termination with ethacridine lactate. J Indian Med Assoc. 1984;82(12):432-4.

5. Laul RM, Mahale AR, Bhattacharya PR. Termination of mid trimester pregnancies with extraovular $0.1 \%$ ethacridine lactate. Accurate method for estimation of blood loss. Role of spartein sulfate. Asia Oceania J Obstet Gynaecol. 1984;10(2):185-9.

6. Bhathena RK, Sheriar NK, Walvekar VR, Guillebaud J. Second trimester pregnancy termination using extra-amniotic ethacridine lactate. $\mathrm{Br} \mathrm{J}$ Obstet Gynaecol. 1990;97(11):1026-9.

7. Kelekci S, Erdemoglu E, Inan I. Randomized study on the effect of adding oxytocin to ethacridine lactate or misoprostol for secondtrimester termination of pregnancy. Acta Obstet Gynecol Scand. 2006; 85(7):825-9.

8. Embrey MP. Prostaglandins in human reproduction. Br Med J (Clin Res Ed). 1981;283(6306):1563-6.

9. Jain JK, Mishell DR Jr. A comparison of intravaginal misoprostol with prostaglandin E2 for termination of second-trimester pregnancy. N Engl J Med. 1994;33(5):290.

10. Chen F, Liu XY, Peng P, Lang JH. Comparison of combination of dinoprostone suppository and ethacridine and ethacridine alone for induction of mid term pregnancy. 2010;32(5):505-8.

11. Choudhary N, Saha SC, Gopalan S. Abortion procedures in a tertiary care institution in India. Int J Gynaecol Obstet. 2005;91(1):81-6.

12. Lalitkumar S, Bygdeman M, Gemzell-Danielsson K. Mid-trimester induced abortion: a review. Hum Reprod Update. 2007;13(1):37-52.

13. Rudolph MI, Cabanillas A, Gomez P, García MA, Villan L. On the mechanism of action of ethodin in inducing myometrium contractions. Gen Pharmacol. 1997;28(3):381-5.

14. El-Refaey H, Calder L, Wheatley DN, Templeton A. Cervical priming with prostaglandin E1 analogues, misoprostol and gemeprost. Lancet. 1994;343(8907):1207-9.

15. Uldbjerg $\mathrm{N}$, Ulmsten $\mathrm{U}$. The physiology of cervical ripening and cervical dilatation and the effect of abortifacient drugs. Baillieres Clin Obstet Gynaecol. 1990;4(2):263-82. 